\title{
Scientists Take on Poetry
}

\section{Stuck with how to present your latest scientific project? Try a poem.}

By Katherine Wright

\rceil oday, poetry and science are often considered to be mutually exclusive career paths. But that wasn't always the case. The mathematician Ada Lovelace and the physicist James Clerk Maxwell were both accomplished poets who wrote rhymes about rainbows and verse about scientific societies. Conversely, the poet John Keats was a licensed surgeon. Combining the two practices fell out of favor in the 1800 s, when science moved from a hobby of the elite to a legitimate profession. But translating research into lyrics, haiku, and other poetic forms is resurging among scientists as they look for alternative ways to inspire others with their findings.

"Poetry is a great tool for interrogating and questioning the world," says Sam Illingworth, a poet and a geoscientist who currently works as a lecturer in science communication at the University of Western Australia. Through workshops and a new science-poetry journal, called Consilience, Illingworth is helping scientists to translate their latest results into poems that can attract appreciation from those outside of their immediate scientific sphere. "There are so many amazing science stories out there that people don't know about because they are hidden in the jargon of scientific papers," he says. "Poetry is a

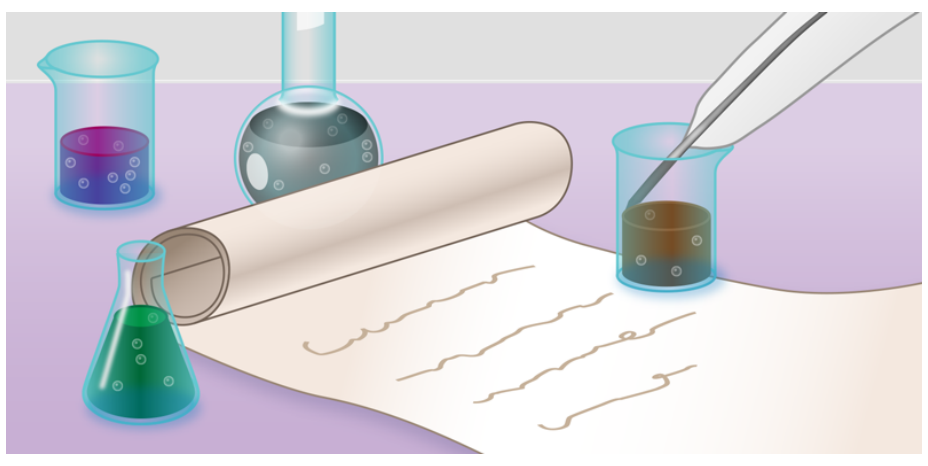

Scientists are trying their hand at poetry in various venues, such as at a recent conference and in a newly formed journal.

Credit: APS/Alan Stonebraker really powerful way to change that and to enable communication to take place."

One scientist who has started using poetry as a communication tool is Stephany Mazon, who studies problems related to gas condensation in the atmosphere at the University of Helsinki in Finland. In May, Mazon joined one of Illingworth's workshops, which took place via Zoom as part of the European Geophysical Union's annual meeting. In the workshop, she, along with 300 other scientists, were split into groups of three. Each group was then tasked with writing a haiku, a 17-syllable-long poem that traditionally focuses on nature.

Mazon was inspired to join the workshop, as she wanted to try her hand at this unconventional method of science communication. "We can't all be Twitter stars," she jokes. Her group only had a few minutes to come up with their haiku, which spotlighted water, a fluid that serendipitously featured in all of the group members' research projects. "It was a lot of fun, and surprisingly easy to write the poem," Mazon says.

Mazon plans to continue writing-with hopes to both incorporate poetry into a children's book about climate change and to use it to share her research with her colleagues. Her dedication is evident from a tattoo on her right wrist with the words "poetical science," a phrase coined by Lovelace to describe her blend of science, imagination, and poetry. "We do a disservice to ourselves to think that scientists can't be artistic and that art can't be used to communicate scientific ideas," Mazon says. "This segregation of fields is, in my opinion, limiting."

That viewpoint is echoed by Illingworth, who thinks science communication initiatives are too often dominated by public lectures with their hands-off PowerPoint slides. "They are set up as unidirectional monologues in which we try to convince an 


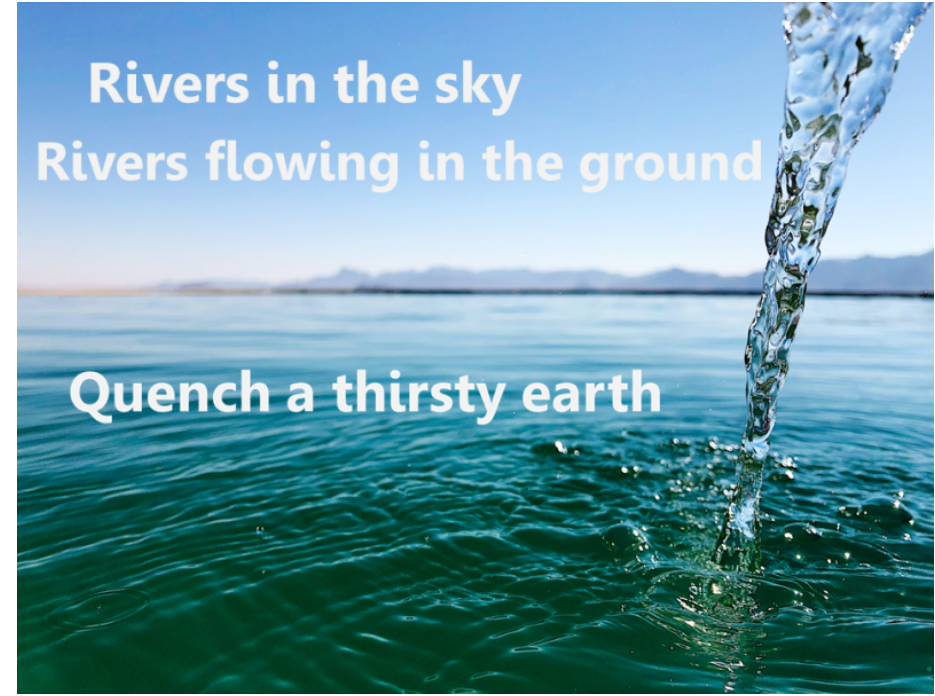

A haiku composed by Stephany Mazon and her colleagues during a workshop at the European Geophysical Union's annual meeting. Credit: Background image: wilpuntimages

audience how great our particular flavor of science is," he says. By contrast, a poem builds on a more common set of experiences. "Poetry levels hierarchies of intellect," Illingworth says. And when science communication involves writing and sharing poems, it invites a two-way dialog between experts and nonexperts.

Scientist-poet Manjula Silva agrees. An educator at Imperial College London with a background in sustainable polymers and recycling, she is part of an ongoing dialog with Dan Simpson, who is the poet-in-residence at Imperial. The duo regularly meet up (virtually) to discuss new findings about the behavior of polymers and to share poems about this material that they are both working on. Poetry provides a way to translate complex scientific concepts into a language that everyone can understand, Silva says.

That possibility is also what inspires the astrophysicist and poet Sunayana Bhargava, who works with Illingworth on the Consilience editorial team and is a researcher at the University of Sussex, UK. "A good science poem is one that calls upon a scientific idea but then tweaks it and elevates it in a way that a simple description can't," she says. For that reason, Bhargava prefers to leave jargon out of her poems, noting that when done poorly, incorporating technical language into a poem can

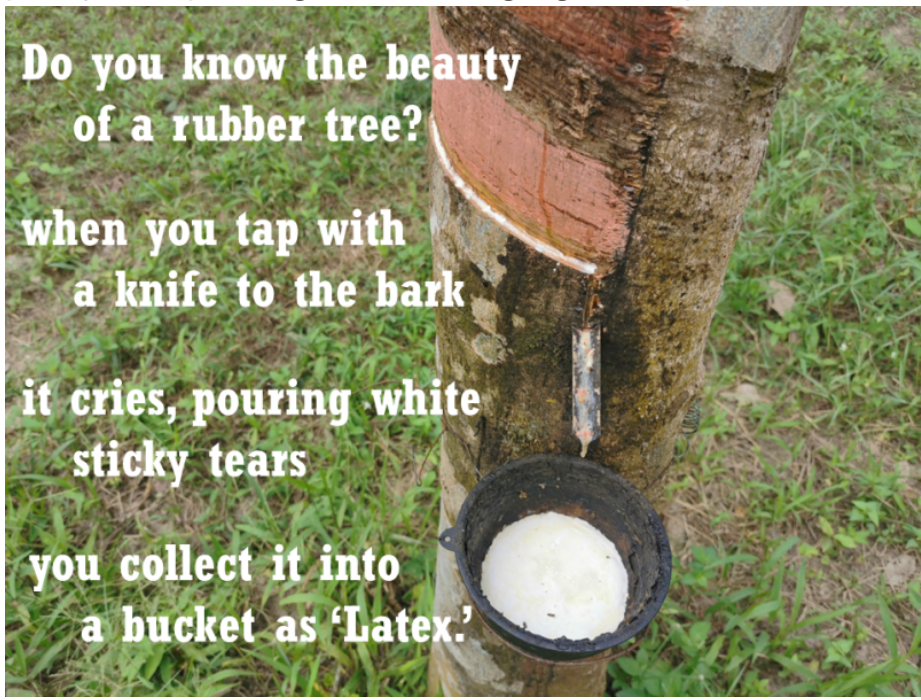

An excerpt from a poem by Manjula Silva.

Credit: Background image: ieang/iStock/Getty images

immediately put a barrier between the poet and the person they are communicating with. "Jargon can alienate people." she says. But she adds, "there are ways to include it that can subvert expectations of what jargon can do in a poem."

Simpson is one poet who does that well. In his showpiece poem "Applied Mathematics"-which is made entirely of scientific phrases-Simpson repurposes technical terms to describe one person's love for another, while always hinting back at the words' original meaning. For example, the poem opens with the line "I love the curvature of your wave form, the way you diverge from the norm."

Scientists and poets are both trying to understand the world and communicate that understanding with others, says Simpson. "The distinction between scientists and the poets is less than people might think. We're all just people with-hopefully-really interesting things to say and to share."

Katherine Wright is a Senior Editor for Physics. 